\title{
A REDUÇÃO DAS DESIGUALDADES NO BRASIL E O OBJETIVO DE DESENVOLVIMENTO SUSTENTÁVEL Nº 10
}

\author{
Renato Braz Mehanna Khamis* \\ Juliana da Silva Alves ${ }^{* *}$
}

\begin{abstract}
RESUMO
O presente trabalho tem como finalidade estudar os itens 10.2 e 10.3 do Objetivo de Desenvolvimento Sustentável - ODS n ${ }^{\circ} 10$ de forma comparativa com os direitos previstos na Constituição Federal de 1988, bem como aferir sua efetividade, como forma identificar o grau de sustentabilidade desenvolvimentista alcançado pelo Brasil e o que seria necessário para atingir o estágio previsto no citado ODS. Para tanto, esta pesquisa será realizada com base no método dedutivo, estruturada em abordagem de natureza aplicada, uma vez que busca oferecer um conhecimento de aplicação prática, dirigido à solução de um problema existente específico. Além disto, seu objetivo é explicativo, pois busca identificar os fatores que permitem a existência do objeto estudado, sendo que, para atingir sua finalidade, adota o procedimento bibliográfico, já que amparado por referências normativas e teóricas publicadas em meio escrito e eletrônico.
\end{abstract}

PALAVRAS CHAVE: Redução, Desigualdades, ODS 10, Igualdade, Isonomia.

\section{ABSTRACT}

The objective of this project is to study items 10.2 and 10.3 of the Sustainable Development Goals - SDG No. 10 in a comparative manner with the rights established in the Brazil's Constitution/1988, as well as to assess its effectiveness, as a way to identify the degree

\footnotetext{
* Mestre em Direito do Estado pela Pontifícia Universidade Católica de São Paulo. Doutor em Direito do Estado pela Pontifícia Universidade Católica de São Paulo. Professor Permanente do Programa de Mestrado em Direito da Saúde da Universidade Santa Cecília. Líder do Grupo de Pesquisa CNPQ "A eficácia dos direitos fundamentais e a efetividade do Direito à Saúde".

** Graduanda em Direito pela Universidade Santa Cecília. Membro do Grupo de Pesquisa CNPQ "A eficácia dos direitos fundamentais e a efetividade do Direito à Saúde".
} 
of developmental sustainability achieved by Brazil and what would be necessary to reach the stage established by the SDG system. In this regard, this research will be based on the deductive method, to inform us on the basis of application, as a matter of practical application, as it seeks a knowledge of practical application, focused at solving a specific existing problem. In addition, its objective and explanatory, since it seeks to identify the factors that allow the existence of the object studied, and, for its own purpose, adopts the bibliographic procedure, since it is supported by normative and theoretical references published in the written and electronic format.

KEYWORDS: Reduction, Inequalities, SDG 10, Equality, Isonomy

\section{INTRODUÇÃ̃o}

Os Objetivos de Desenvolvimento Sustentável - ODS são metas traçadas pela Organização das Nações Unidas durante a Cúpula das Nações Unidas sobre o Desenvolvimento Sustentável em setembro do ano de 2015. Compõem tais traçados 17 objetivos com 169 metas, a serem atingidas até o ano de 2030.

Como principal fonte para se atingir os efeitos previstos nos ODS, utiliza-se a aplicação do princípio da igualdade, que está elencado no artigo $5^{\circ}$ da Constituição Federal, dentro do qual destacamos aqueles incisos de interesse para a presente pesquisa, quais sejam: I,VI, VII, IX, XLI, XLII. Além do direito pátrio, podese encontrar fundamentação sobre o tema na Declaração Universal dos Direitos humanos em seus artigos $1^{\circ}, 2^{\circ}, 7^{\circ}$ e 25 .

Na sociedade atual há constante evolução em alguns aspectos, porém, infelizmente têm-se deixado a desejar o engajamento das entidades governamentais e dos próprios poderes em relação à uma busca empenhada de formas para garantir a igualdade entre os povos. Processos discriminatórios por diversas questões acabam atingindo a qualquer ser humano que não se encaixe no padrão de "normalidade" pré determinado, assim ferindo o principio da igualdade, normatizado na Constituição Federal.

Relatos frequentes são veiculados nas mídias sobre situações discriminatórias contra negros, questões de orientação sexual, opção religiosa, dentre outros, além da veiculação de casos de comunidades extremamente pobres, onde ainda não se tem acesso à saneamento 
básico e ainda há uma grande quantidade de seres humanos passando fome, além da recente atualização no Índice de GINI (Fundação Getúlio Vargas), que mede a desigualdade nos países, onde aponta que em 22 anos pela primeira vez há um forte crescimento na desigualdade, nos levam ao entendimento de que há, mais do que nunca, uma necessidade pulsante de se criar legislações que protejam tais minorias, assim como efetivar seus direitos constitucionais já garantidos, posto que, ninguém poderá sofrer nenhum tipo de discriminação, haja vista os dispositivos legais da Constituição da Republica Federativa Do Brasil.

Dessa forma, a comparação da realidade nacional em face dos objetivos e metas estipulados pelos ODS são elementos que justificam a realização de pesquisa científica acerca do problema indicado.

O objetivo central do presente artigo é mesclar os itens 10.2 e 10.3 do Objetivo de Desenvolvimento Sustentável nº10, através do entendimento de que o item 10.3 torna-se de maneira clara um mecanismo para efetivação dos direitos elencados no item anterior.

Por fim, trata-se de pesquisa realizada com base no método dedutivo, que está estruturada em abordagem de natureza aplicada, uma vez que busca oferecer um conhecimento de aplicação prática, dirigido à solução de um problema existente específico. Além disto, seu objetivo é explicativo, pois busca identificar os fatores que permitem a existência do objeto estudado, sendo que, para atingir sua finalidade, adota o procedimento bibliográfico, já que amparado por referências normativas e teóricas publicadas em meio escrito e eletrônico.

\section{O QUE SÃO IGUALDADES}

O conceito jurídico de igualdade é elencado por Celso Antônio Bandeira de Mello em sua Obra "O conteúdo Jurídico do Princípio da igualdade". Segundo ele, "A igualdade é princípio que visa a duplo objetivo, a saber: de um lado propiciar garantia individual contra perseguições, e de outro, tolher favoritismos.", demonstrando assim que a igualdade tem o objetivo de exercer direitos e garantir direitos. Neste sentido, o relatório "A Distância que nos Une" (OXFAM, 2017, p.11), expõe o que segue: 
Uma sociedade igualitária não só oferece oportunidades iguais aos seus cidadãos e cidadãs, mas também se preocupa com condições de vida menos desiguais em sua população. Tal como define a meta 10.3 do ODS 10, é fundamental "garantir a igualdade de oportunidades e reduzir as desigualdades de resultados".

No caso brasileiro, a despeito de avanços na redução de desigualdades, permanece uma situação extrema, em que poucos detêm a maior parte dos recursos e das oportunidades - incluindo os recursos políticos que limitam e até mesmo impedem a mobilidade social.

Esta situação é injusta e danosa a toda sociedade. Ela joga contra direitos individuais e coletivos, e de populações vulneráveis. Ela prejudica a classe média e enfraquece nossa economia, nossa democracia, e é terreno fértil para o florescimento da violência.

Isso posto, a Constituição Federal de 1988 preceitua em seu artigo $5^{\circ}$ o princípio supracitado, idade, definindo que todo ser humano terá direitos iguais, e que ninguém deverá sofrer discriminação por suas escolhas, in fine incisos pertinentes:

Art. $5^{\circ}$ Todos são iguais perante a lei, sem distinção de qualquer natureza, garantindo-se aos brasileiros e aos estrangeiros residentes no País a inviolabilidade do direito à vida, à liberdade, à igualdade, à segurança e à propriedade, nos termos seguintes:

I - homens e mulheres são iguais em direitos e obrigações, nos termos desta Constituição;

VI - é inviolável a liberdade de consciência e de crença, sendo assegurado o livre exercício dos cultos religiosos e garantida, na forma da lei, a proteção aos locais de culto e a suas liturgias;

VIII - ninguém será privado de direitos por motivo de crença religiosa ou de convicção filosófica ou política, salvo se as invocar para eximir-se de obrigação legal a todos imposta e recusar-se a cumprir prestação alternativa, fixada em lei;

IX - é livre a expressão da atividade intelectual, artística, científica e de comunicação, independentemente de censura ou licença;

XLI - a lei punirá qualquer discriminação atentatória dos direitos e liberdades fundamentais;

XLII - a prática do racismo constitui crime inafiançável e imprescritível, sujeito à pena de reclusão, nos termos da lei;"” 
Além da letra fria da lei, pode-se encontrar fundamentação sobre o tema da igualdade na Declaração Universal Dos Direitos Humanos, e em diversos outros tratados e declarações. ${ }^{1}$

Independentemente de haver legislação assegurando o direito à igualdade, relatos frequentes são veiculados nas mídias sobre situações discriminatórias contra negros, questões de orientação sexual, opção religiosa, dentre outros, além da veiculação de casos de comunidades extremamente pobres, onde ainda não se tem acesso à saneamento básico e ainda há uma grande quantidade de seres humanos passando fome, além da recente atualização no Indíce de GINI (Fundação Getúlio Vargas), que mede a desigualdade nos países, onde aponta que em 22 anos pela primeira vez há um forte crescimento na desigualdade, nos levam ao entendimento de que há, mais do que nunca, uma necessidade pulsante de se criar legislações que protejam tais minorias, assim como efetivar seus direitos constitucionais já garantidos, posto que, ninguém poderá sofrer nenhum tipo de discriminação, haja vista os dispositivos legais da Constituição da Republica Federativa Do Brasil.

\section{O OBJETIVO DE DESENVOLVIMENTO SUSTENTÁVEL $\mathrm{N}^{\circ} 10$ E OS ITENS 10.2 E 10.3 COMO EFETIVAÇÃO DA REDUÇÃO DAS DESIGUALDADES}

Os Objetivos de Desenvolvimento Sustentável são as metas traçadas pela Organização das Nações Unidas com interesse em alcançar a agenda 2030, que foi criada no ano de 2015, quando líderes mundiais, durante a Cúpula das Nações Unidas sobre o Desenvolvimento Sustentável, na sede da ONU em Nova York determinaram um plano de ação, baseado nos Objetivos do Milênio, com a finalidade de que, até o ano de 2030, fosse possível a erradicação da pobreza, proteção do planeta e garantia de paz e prosperidade a todos.

\footnotetext{
${ }^{1}$ Declaração dos direitos do homem e cidadão. Declaração das Nações Unidas sobre a Eliminação de Todas as Formas de Discriminação Racial.
} 
FIGURA 1 - Objetivos do Milênio.

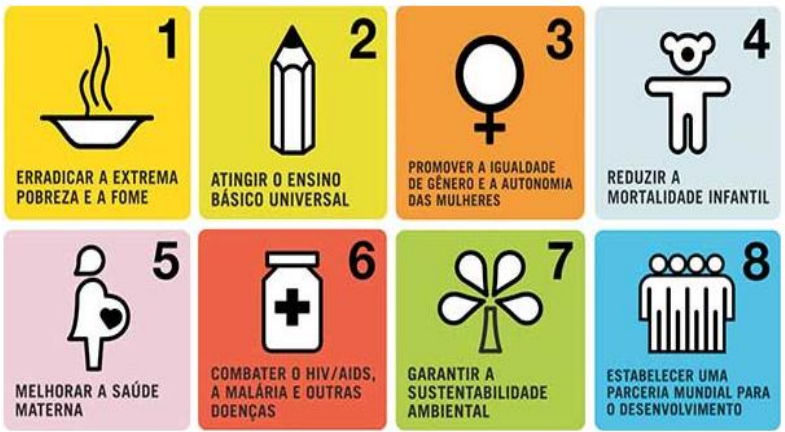

FONTE: <http://www.agenda2030.com.br/sobre/>. Acesso em 04/03/2018, $21 \mathrm{~h} 33 \mathrm{~min}$.

$\mathrm{Na}$ concepção da ONU, desenvolvimento sustentável é "O desenvolvimento que procura satisfazer as necessidades da geração atual, sem comprometer a capacidade das gerações futuras de satisfazerem as suas próprias necessidades." (Agenda 2030, ONU, 2018). Portanto, o desenvolvimento sustentável deve ser compreendido como uma responsabilidade pelas ações, omissões e suas consequências, preservando a geração atual e melhorando condições às gerações futuras.

Para alcançar tais objetivos, a agenda 2030, que se originou do documento "Transformando o Nosso Mundo: A Agenda 2030 para o Desenvolvimento Sustentável", pontuou 17 medidas a serem tomadas por todos, nomeando-as como "OBJETIVOS DE DESENVOLVIMENTO SUSTENTÁVEL". Como resultado do cumprimento de tais metas, esta seria a primeira geração a erradicar a pobreza extrema.

Para se atingir os objetivos dos chamados ODS estão previstas ações mundiais nas áreas de segurança alimentar, agricultura, saúde, educação, igualdade de gênero, redução das desigualdades, energia, água e saneamento, padrões sustentáveis de produção e de consumo, mudança do clima, cidades sustentáveis, proteção e uso sustentável dos oceanos e dos ecossistemas terrestres, crescimento econômico inclusivo, infraestrutura, industrialização, entre outros.

Como forma de organização, os temas dos Objetivos de Desenvolvimento Sustentável são divididos em quatro "setores": 
1 - social: trata de matérias relacionadas às necessidades humanas, qualidade de vida, educação, saúde e etc.

2 - econômica: versa sobre matérias relativas ao uso e esgotamento de recursos naturais, energia sustentável, produção de registros, dentre outros.

3 - Ambiental: os objetivos aqui abraçados, observam a preservação e conservação do meio ambiente, proteção da biodiversidade, das florestas, utilização sustentável dos recursos marinhos, dentre outros.

4 - Institucional: este setor visa uma maneira efetiva, uma capacidade de colocar em prática os Objetivos de Desenvolvimento Sustentável.

Enumerados de 01 à 17, os ODS são: ODS 1 - Erradicação da pobreza; ODS 2 - Fome zero; ODS 3 - Boa saúde e bem estar; ODS 4 - Educação de qualidade; ODS 5 - Igualdade de Gênero; ODS 6 Água limpa e saneamento; ODS 7 - Energia acessível e limpa; ODS 8 - Emprego digno e crescimento econômico; ODS 9 - Indústria, inovação e infraestrutura; ODS 10 - Redução das desigualdades; ODS 11 - Cidades e comunidades sustentáveis; ODS 12 - Consumo e produção sustentáveis; ODS 13 - Combate às alterações climáticas; ODS 14 - Vida debaixo d'água; ODS 15 - Vida sobre a terra; ODS 16 - Paz, justiça e instituições fortes; ODS 17 - Parcerias em prol das metas.

O objetivo de Desenvolvimento Sustentável $n^{\circ} 10$, objeto central deste projeto de pesquisa, versa sobre a redução das desigualdades entre países e no país, in fine:

10.1 até 2030, progressivamente alcançar e sustentar o crescimento da renda dos $40 \%$ da população mais pobre a uma taxa maior que a média nacional;

10.2 até 2030, empoderar e promover a inclusão social, econômica e política de todos, independentemente da idade, gênero, deficiência, raça, etnia, origem, religião, condição econômica ou outra;

10.3 garantir a igualdade de oportunidades e reduzir as desigualdades de resultado, inclusive por meio da eliminação de leis, políticas e práticas discriminatórias e promover legislação, políticas e ações adequadas a este respeito;

10.4 adotar políticas, especialmente fiscal, salarial e políticas de proteção social, e alcançar progressivamente uma maior igualdade; 
10.5 melhorar a regulamentação e monitoramento dos mercados e instituições financeiras globais, e fortalecer a implementação de tais regulamentações;

10.6 assegurar uma representação e voz mais forte dos países em desenvolvimento em tomadas de decisão nas instituições econômicas e financeiras internacionais globais, a fim de produzir instituições mais eficazes, críveis, responsáveis e legítimas;

10.7 facilitar a migração e a mobilidade ordenada, segura, regular e responsável das pessoas, inclusive por meio da implementação de políticas de migração planejadas e bem geridas;

10.a implementar o princípio do tratamento especial e diferenciado para países em desenvolvimento, em particular os países menos desenvolvidos, em conformidade com os acordos da OMC;

10.b incentivar AOD e fluxos financeiros, incluindo o investimento externo direto, para os estados onde a necessidade é maior, em particular os países menos desenvolvidos, os países africanos, SIDS e LLDCs, de acordo com seus planos e programas nacionais;

10.c até 2030, reduzir para menos de $3 \%$ os custos de transação de remessas dos migrantes e eliminar "corredores de remessas" com custos superiores a $5 \%$.

O entendimento é de que, para se reduzir as desigualdades, deve-se assegurar renda às populações mais pobres, promover a inclusão social e política, adotar políticas de proteção salarial e eliminar leis discriminatórias, criando leis mais adequadas, além de fiscalização e regulamentação dos mercados financeiros para que não concentrem a renda em demasia.

O item 10.2 está intimamente ligado à participação social. Através do empoderamento e da inclusão social, com medidas efetivas como investimento em educação, saúde, lazer, cultura entre outros, o ser humano torna-se um cidadão com conhecimento, entendimentos mais claros e amplos e noções, ainda que básicas, de direitos e deveres.

10.2 até 2030, empoderar e promover a inclusão social, econômica e política de todos, independentemente da idade, gênero, deficiência, raça, etnia, origem, religião, condição econômica ou outra.

O item 10.3 busca, através da eliminação de leis, políticas e práticas discriminatórias, a criação de legislação e políticas públicas inclusivas. 
10.3 garantir a igualdade de oportunidades e reduzir as desigualdades de resultado, inclusive por meio da eliminação de leis, políticas e práticas discriminatórias e promover legislação, políticas e ações adequadas a este respeito.

Desta feita, esclarece-se que, se, pelo menos os itens 10.2 e 10.3 do referido ODS forem efetivamente cumpridos, praticados, haverá uma redução brusca nas desigualdades.

Através da promoção da inclusão social e do empoderamento, haveria uma potencialização da conscientização sobre direitos sociais e civis, tornando os cidadãos mais preparados para lutar e reivindicar seus direitos e cumprir, também, com seus deveres.

A inclusão social, econômica e política pode ser entendida como o conjunto de meios e ações que combatem a exclusão aos benefícios da vida em sociedade, oferecendo igual acesso à bens e serviços para todos; Esta exclusão é causada por diferenças de classe social, educação, idade, deficiência, gênero, religião e preconceitos em geral. Neste sentido, há a necessidade de utilização do item 10.3 em complementação ao item 10.2.

No item 10.3, vislumbra-se, inicialmente, a exclusão de políticas públicas e leis que gerem quaisquer tipos de exclusão. Outro detalhe importante é a necessidade de criação de legislações e políticas públicas inclusivas, que afastem as desigualdades e exclusões de quaisquer formas, como por exemplo, a Declaração Universal De Direitos Humanos, que foi aprovada na Assembleia Geral da ONU em 1948, e é considerada até hoje como base da luta contra a opressão e discriminação das pessoas, tendo como fundamento básico a defesa da igualdade e da dignidade da pessoa humana. Em alguns de seus artigos, fica explícita a proteção à Igualdade, in fine:

Artigo $1^{\circ}$ : Todas as pessoas nascem livres e iguais em dignidade e direitos. São dotadas de razão e consciência e devem agir em relação umas às outras com espírito de fraternidade.

Artigo $2^{\circ}$ :Toda pessoa tem capacidade para gozar os direitos e as liberdades estabelecidas nesta Declaração, sem distinção de qualquer espécie, seja de raça, cor, sexo, língua, religião, opinião política ou de outra natureza, origem nacional ou social, riqueza, nascimento, ou qualquer outra condição. 
Não será tampouco feita qualquer distinção fundada na condição política, jurídica ou internacional do país ou território a que pertença uma pessoa, quer se trate de um território independente, sob tutela, sem governo próprio, quer sujeito a qualquer outra limitação de soberania.

\section{Artigo $7^{\circ}$}

Todos são iguais perante a lei e têm direito, sem qualquer distinção, a igual proteção da lei. Todos têm direito a igual proteção contra qualquer discriminação que viole a presente Declaração e contra qualquer incitamento a tal discriminação.

\section{Artigo 25}

$\S 1$. Toda pessoa tem direito a um padrão de vida capaz de assegurar a si e a sua família saúde e bem-estar, inclusive alimentação, vestuário, habitação, cuidados médicos e os serviços sociais indispensáveis, e direito à segurança em caso de desemprego, doença, invalidez, viuvez, velhice ou outros casos de perda dos meios de subsistência em circunstâncias fora de seu controle.”

Cabe ressaltar que, além da Declaração supra, o Pacto Internacional sobre Direitos Civis e Políticos assegura o direito à igualdade, sendo importante instrumento de estudo:

Artigo $2^{\circ}$ :

1. Os Estados Partes do presente pacto comprometem-se a respeitar e garantir a todos os indivíduos que se achem em seu território e que estejam sujeitos a sua jurisdição os direitos reconhecidos no presente Pacto, sem discriminação alguma por motivo de raça, cor, sexo. língua, religião, opinião política ou de outra natureza, origem nacional ou social, situação econômica, nascimento ou qualquer condição.

2. Na ausência de medidas legislativas ou de outra natureza destinadas a tornar efetivos os direitos reconhecidos no presente Pacto, os Estados Partes do presente Pacto comprometem-se a tomar as providências necessárias com vistas a adotá-las, levando em consideração seus respectivos procedimentos constitucionais e as disposições do presente Pacto.

3. Os Estados Partes do presente Pacto comprometem-se a:

a) Garantir que toda pessoa, cujos direitos e liberdades reconhecidos no presente Pacto tenham sido violados, possa de um recurso efetivo, mesmo que a violência tenha sido perpetra por pessoas que agiam no exercício de funções oficiais; 
b) Garantir que toda pessoa que interpuser tal recurso terá seu direito determinado pela competente autoridade judicial, administrativa ou legislativa ou por qualquer outra autoridade competente prevista no ordenamento jurídico do Estado em questão; e a desenvolver as possibilidades de recurso judicial;

c) Garantir o cumprimento, pelas autoridades competentes, de qualquer decisão que julgar procedente tal recurso.

Conforme o artigo $2^{\circ}$ do Pacto Internacional sobre direitos Civis e Políticos, que está interligado com o item 10.3, as prefeituras e Governos dos Estados, deverá haver a criação de comissões e legislações que visem reduzir as desigualdades de acordo com as necessidades específicas de cada região.

$\mathrm{Na}$ cidade de Santos, podemos citar, como exemplo, a "Comissão da Diversidade Sexual de Santos", que, além de reunir seus membros mensalmente para discutir assuntos pertinentes à questões de identidade de gênero e orientação sexual, em encontros abertos à toda a população, promove capacitações aos serviços públicos e à população em geral, espalhando, desta forma, conhecimento aos interessados, gerando uma redução no preconceito e assim, auxiliando na redução das desigualdades.

A Assembleia Legislativa do Estado de São Paulo possui diversas comissões permanentes, no sentido da redução das desigualdades, pertinente salientar a Comissão de Defesa dos Direitos da Pessoa Humana, da Cidadania, da Participação e das Questões Sociais, que, conforme site da ALESP, tem a finalidade de, priorizando a participação popular e de autoridades que tenham conhecimento sobre a matéria, criar e fortificar ações contra práticas discriminatórias, preconceitos, violação da dignidade da pessoa humana, dentre outros.

À Comissão de Defesa dos Direitos da Pessoa Humana, da Cidadania, da Participação e das Questões Sociais compete opinar sobre proposições e assuntos que digam respeito aos direitos humanos, inclusive ouvindo pessoas e autoridades que tenham interesse e conhecimento sobre a matéria, e ainda às ações discriminatórias, ao preconceito, à violação da dignidade da pessoa humana e menores infratores e à defesa da cidadania, colaborando com entidades não governamentais nacionais e internacionais que 
atuem nestas áreas e analisando propostas legislativas encaminhadas pelo Banco de Projetos, apresentadas por pessoa física, associações, órgãos de classe, sindicatos e entidades organizadas da sociedade civil, exceto partidos políticos com representação na Assembleia Legislativa; bem como sobre a organização ou reorganização de repartições da administração direta ou indireta aplicadas a esses fins.

Em relação ao Governo Federal, podemos citar os programas "Bolsa Família", "Minha Casa, minha vida", "Programa FAT Fundo de Amparo ao Trabalhador", "PROUNI", "PRONATEC Programa Nacional de Acesso ao Ensino Técnico e Emprego", "Ciência Sem Fronteiras", merecendo destaque ao tema, o programa "Brasil Sem Miséria", que tem como uma de suas principais ações o "Brasil Carinhoso - Primeira infância", que é responsável por utilizar a renda possibilitanto o aumento de vagas em creches, melhoria na alimentação fornecida, tendo em vista uma melhoria na condição geral das crianças de 0 à 6 anos.

O que se pode observar, é que, ainda assim, há uma enorme desigualdade no país, demonstrando a clara ausência de motivação do poder público no sentido de incentivar à criação de legislações e políticas públicas interessadas em esclarecer, educar, fornecer cultura, lazer, esporte, dentre outros, aos cidadãos, independentemente de seu grau de riqueza, da cor de sua pele, de sua renda, de sua identidade de gênero, religião ou qualquer outra circunstância que possa diferenciálo do padrão estereotipado pela sociedade.

Assim, fica clara a não utilização do $\operatorname{ODS} \mathrm{n}^{\circ} 10$, itens 10.2 e 10.3 pelo poder público como forma de efetivação da redução das desigualdades e de todos os outros Objetivos de Desenvolvimento Sustentável.

\section{AS DESIGUALDADES NO BRASIL}

O Brasil é um dos países mais desiguais do mundo. Há diferenças estrondosas nos níveis de riqueza, renda, escolaridade, raça, cor, gênero, que devem ser repelidas pelo poder publico e pela sociedade em geral. Combater as desigualdades é permitir e gerar a possibilidade de acesso à direitos básicos que todo ser humano possui, e depende, necessariamente, do empoderamento de toda a sociedade, para que, assim, haja participação em diversos setores. 
Em sua obra "A riqueza de poucos beneficia todos nós?" Zygmunt Bauman apresenta uma reflexão e um estudo acerca das questões de desigualdade em todo o mundo. Inicialmente, aponta que um estudo do World Institute For Development Economics Research, da universidade das Nações unidas, relatando que o $1 \%$ mais rico de adultos possuía $40 \%$ dos bens globais em 2000 , e que os $10 \%$ mais ricos respondiam por $85 \%$ do total da riqueza do mundo.

Bauman aponta ainda que o individualismo é a ideologia que justifica o enriquecimento rápido dos que já são muito ricos, impulsionando assim, um crescimento desproporcional das desigualdades sociais:

Em quase toda parte do mundo a desigualdade cresce rapidamente, e isso significa, que os ricos, em particular os muito ricos, ficam mais ricos, enquanto os pobres, em particular, os muito pobres, ficam mais pobres. (BAUMAN, 2015, p.19)

As pessoas não podem mudar essas realidades sozinhas, desejar que desapareçam, livrar-se delas com argumentos nem ignorá-las. Por isso, elas ficam com poucas alternativas além de seguir os padrões de comportamento. [...] É por isso que, com lamentável frequência, nós confundimos essas realidades [...] com a natureza das coisas, natureza que nenhuma faculdade humana pode questionar ou reformar. (BAUMAN, 2015, pp.37-38)

Em análise ao "Relatório Nacional Voluntário sobre os Objetivos de Desenvolvimento Sustentável”, pode-se observar que os níveis de escolaridade do Brasileiro permanecem diminutos. Apenas $10,6 \%$ da população possui ensino superior completo, enquanto, 43,5\% da população não possui nenhuma instrução/escolaridade. 


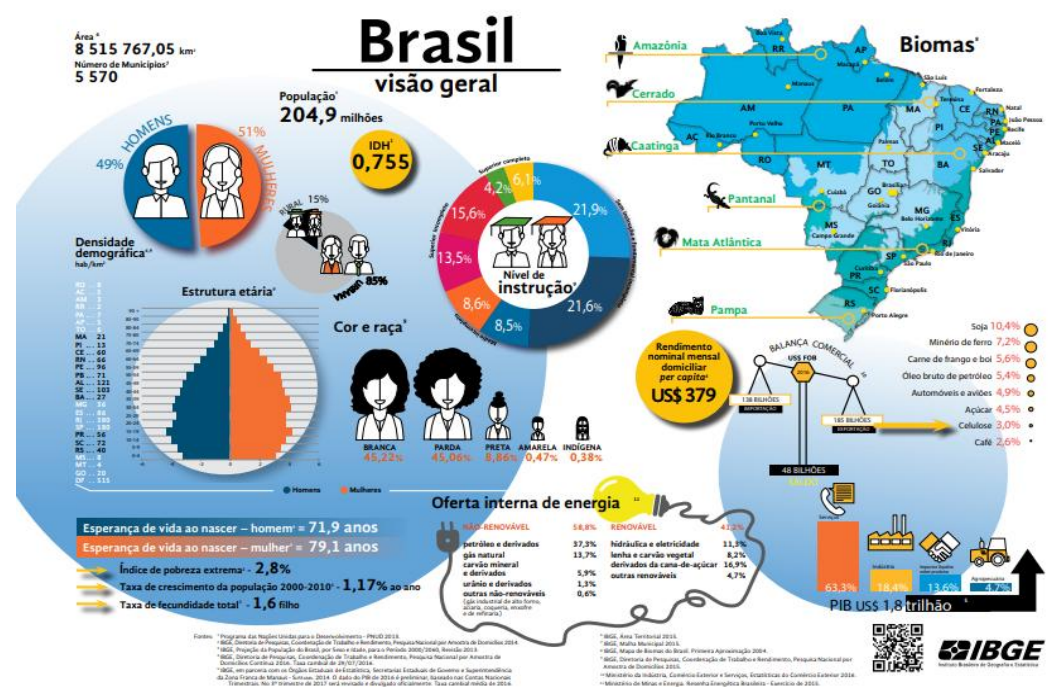

Fonte: Relatório Nacional Voluntário sobre os Objetivos de Desenvolvimento Sustentável, p. 18.

Ainda sobre o "Relatório Nacional Voluntário sobre os Objetivos de Desenvolvimento Sustentável", pode-se observar que a temática central da presente pesquisa, qual seja, os itens 10.2 e 10.3 do Objetivo de Desenvolvimento Sustentável no $10-$ REDUÇÃO DAS DESIGUALDADES, é um caminho claro para a efetivação de todos os ODS, sendo utilizados pelo próprio poder público como estratégias para incorporar a agenda 2030, através da elaboração do diagnóstico brasileiro, passando pelo estabelecimento de prioridades nacionais, mapeamento de políticas públicas, análise da legislação com enfoque na criação e alteração das leis para que se adequem aos Objetivos de Desenvolvimento Sustentável, vínculo dos planos nacionais às metas dos ODS, tendo assim, uma adequação das metas da agenda 2030, e uma possível maior eficácia (ainda que não plena) em todos os setores propostos pela Organização das Nações Unidas. 


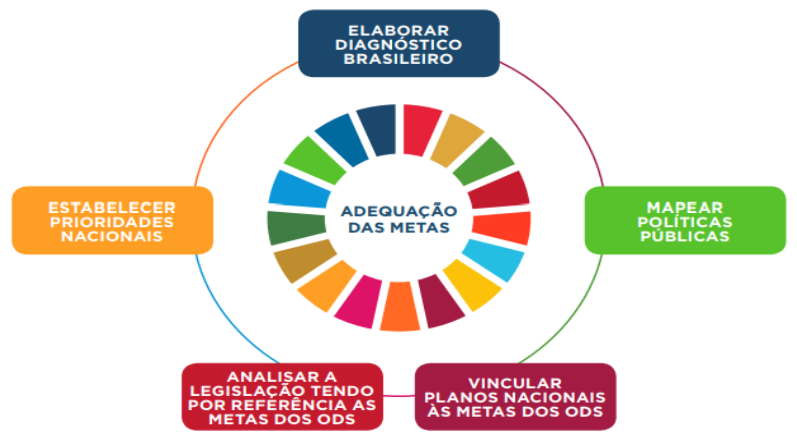

Algumas propostas do relatório supramencionado caminham lado a lado com os itens estudados neste projeto de pesquisa, como o engajamento do setor privado, criação de comissões subnacionais, capacitação de gestores públicos, criação de comissão subnacionais, elaboração de relatórios de monitoramento.

Acerca do Plano Plurianual (PPA), que é o principal instrumento de planejamento a médio prazo das ações governamentais, pode-se verificar uma razoável correspondência dos tributos do PPA com os ministérios responsáveis pela implementação de cada um dos ODS.

GRÁFICOS 3 n Número de atributos do PPA 2016-2019 relacionados com os ODS.

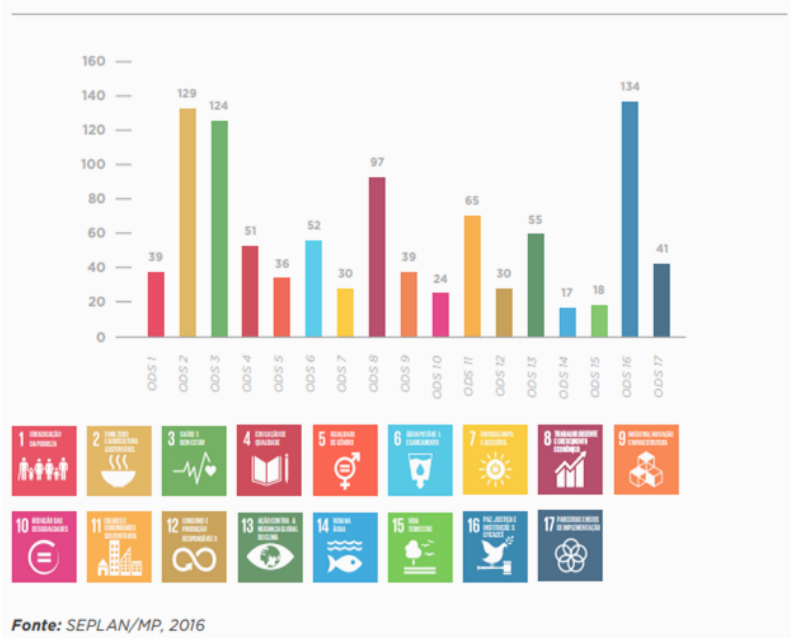


Derradeiramente, importante salientar a existência e organização da Comissão Nacional dos ODS, conforme gráfico abaixo:

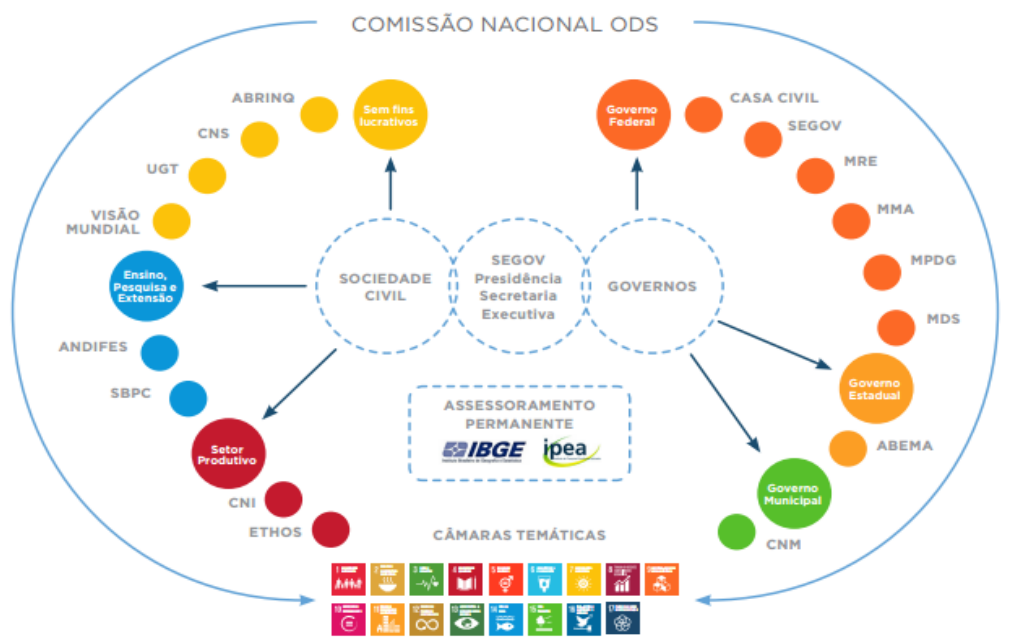

Figura 4: Composição da Comissão Nacional para os Objetivos de Desenvolvimento Sustentável

Outrossim, conforme análise do relatório "A distância que nos une", da OXFAM, publicado em setembro de 2017, foi possível constatar que, apesar das ações supracitadas, as questões de desigualdades permanecem intensas.

Em relação à renda, o $1 \%$ mais rico da população recebe, em média, mais de $25 \%$ de toda a renda nacional, e os $5 \%$ mais ricos possuem o mesmo que os demais $95 \%$ da população. Ainda acerca desta temática, a situação dos negros é ainda mais grave: entre as pessoas que recebem até 1,5 salário mínimo, estão $67 \%$ dos negros brasileiros, em contraste com menos de $45 \%$ dos brancos. Cerca de $80 \%$ dos negros recebem até 02 salários mínimos por mês. Para cada negro com rendimento acima de 10 salários mínimos, há quatro brancos. Outro dado importante é que, no início de 2017, mais de 16 milhões de pessoas no país permaneciam vivendo abaixo da linha da pobreza, demonstrando a discrepância na distribuição de renda. $\mathrm{O}$ relatório conclui que, se mantido o ritmo de inclusão, em equiparação à renda média dos brancos ocorrerá somente em 2089. 
Sobre a desigualdade de riqueza, o relatório observa que o $1 \%$ mais rico concentra $48 \%$ de toda a riqueza nacional e os $10 \%$ mais ricos possuem $74 \%$.

Pertinente ainda ressaltar a desigualdade na oferta de serviços essenciais, tais como acesso a energia elétrica, água encanada, coleta de esgotos, entre outros. A cobertura de acesso a água alcança 94\% para quem está entre os $5 \%$ mais ricos, e cai para $62 \%$ quando se trata dos $5 \%$ mais pobres.

Conforme o gráfico abaixo, a maior parte dos gastos do Governo foi com a previdência, enquanto que, os investimentos em educação, saúde, assistência social, trabalho e emprego, saneamento básico e habitação, foram ínfimos, demonstrando claramente a opção de atenção governamental.

\section{// GRAFICO 15.}

Brasil - Participação por rubrica no total de gastos sociais - 2015
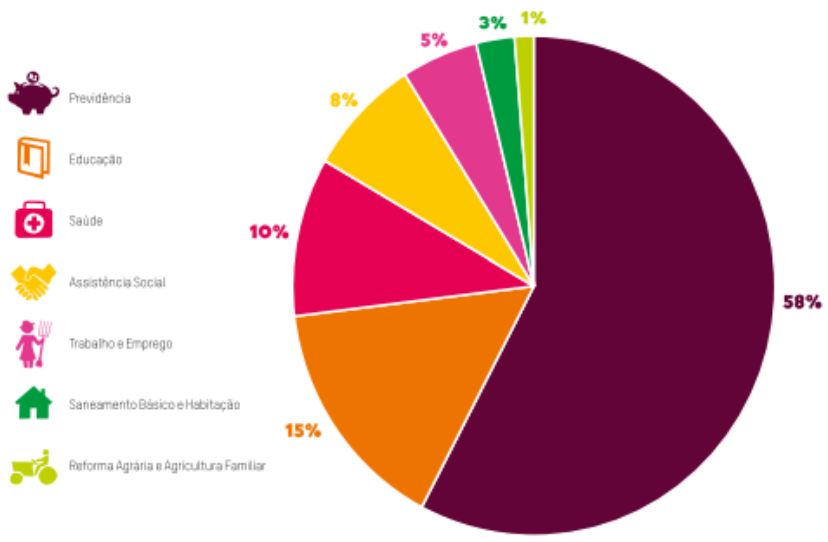

Fente: STN 2016

FONTE: relatório “A distância que nos une”- OXFAM, p. 55.

Observa-se que, as desigualdades no país permanecem em nível alto, e crescentes, o que demonstra que ainda há longo caminho à ser percorrido para se atingir o ODS n ${ }^{\circ} 10$. 


\section{CONCLUSÃO}

Desta feita, analisadas todos os índices discrepantes de desigualdades de renda, riqueza, acesso aos serviços essenciais, gênero, sociais, econômicas, culturais, dentre outros, conclui-se que o caminho para a efetivação da agenda 2030, de todos os Objetivos de Desenvolvimento Sustentável, especialmente o Objetivo no 10 , é longo e permanece distante, observando-se que, dificilmente, as metas traçadas serão atingidas até o ano de 2030.

Por derradeiro, pode-se perceber que o Estado não possui políticas públicas suficientes e eficazes para uma verdadeira redução nas desigualdades, mesmo com as ações supracitadas, não se conseguiu chegar, até hoje, a uma redução significativa nas desigualdades, e por tanto, entende-se que o Poder Público não se utiliza do objetivo de desenvolvimento sustentável $\mathrm{n}^{\circ} 10$, itens 10.2 e 10.3 como forma de efetivação da meta de redução das desigualdades.

\section{REFERÊNCIAS}

BARBOSA, Julio Cesar Tadeu. $O$ que é justiça. São Paulo: Brasiliense, 1984. (Primeiros Passos)

BAUMAN, Zygmunt. A riqueza de poucos beneficia todos nós?. São Paulo: Zahar, 2015.

BAUMAN, Zygmunt; BORDONI, Carlo Zahar. Estado de Crise. São Paulo: Zahar, 2016.

BITTAR, Eduardo Carlos Bianca. Reconhecimento e direito à diferença: teoria crítica, diversidade e cultura dos direitos humanos. Revista da faculdade de Direito da Universidade de São Paulo, São Paulo, v. 104, 2009.

BRASIL. Constituição Federal, disponível em: 〈http://www.planalto.gov.br/ccivil_03/constituicao/constituicao.htm〉. Acesso em 25 abr. 2017.

BRASIL. Declaração universal direitos humanos, disponível em: <http://www.direitoshumanos.usp.br/index.php/Declara\%C3\%A7\%C3\%A3 o-Universal-dos-Direitos-Humanos/declaracao-universal-dos-direitoshumanos.html>. Acesso em 26 abr. 2017.

BRASIL. Convenção americana de direitos humanos, Pacto de San José da Costa Rica, disponível em $<$ http://www.pge.sp.gov.br/centrodeestudos/bibliotecavirtual/instrumentos /sanjose.htm> 
BRASIL. Declaração sobre a raça e preconceitos raciais, disponível em: $<$ http://www.direitoshumanos.usp.br/index.php/UNESCO-

Organiza\%C3\%A7\%C3\%A3o-das-Na\%C3\%A7\%C3\%B5es-Unidas-paraa-Educa\%C3\%A7\%C3\%A3o-Ci\%C3\%AAncia-e-Cultura/declaracao-sobrea-raca-e-os-preconceitos-raciais.html>. Acesso em 28 abr. 2017.

BRASIL. Decreto $n^{0}$ 591, de 6 de julho de 1992. Pacto Internacional dos Direitos Econômicos, Sociais e Culturais, disponível em: <http://www.planalto.gov.br/ccivil_03/decreto/1990-1994/d0591.htm>. Acesso em 23 abr. 2017.

BRASIL. Decreto $N^{0}$ 592, de 6 de julho de 1992. Pacto Internacional dos Direitos Civis e Políticos, disponível em: <http://www.planalto.gov.br/ccivil_03/decreto/1990-1994/d0592.htm>. Acesso em 27 abr. 2017.

BRASIL. Programas de Governo. Disponível em <http://www.programadogoverno.org/>. Acesso em 18 mar. 2018.

BRASIL. Relatório voluntário nacional sobre os ODS, disponível em: <http://www.secretariadegoverno.gov.br/snas-

documentos/relatoriovoluntario_brasil2017port.pdf>. Acesso em 22 fev. 2018.

COMPARATO, Fábio Konder. Os Direitos Humanos na Declaração Universal de 1948 e na Constituição Brasileira em Vigor, disponível em: <escoladegoverno.org.br/artigos/115-direitos-humanos-declaracao-1948>. Acesso em 22 abr. 2017.

COUTO SILVA, Vitor Hugo Miro; DE FRANÇA, João Mário Santos; PINHO NETO, Valdemar Rodrigues De. Capital humano e desigualdade salarial no Brasil: uma análise de decomposição para o período 1995-2014. Disponível em: <http://www.scielo.br/scielo.php?script=sci_arttext\&pid=S0101$41612016000300579 \&$ lang=pt>. Acesso em 29 abr. 2017.

CRUZ, Álvaro Ricardo de Souza. $O$ direito a diferença. As ações afirmativas como mecanismo de inclusão social de mulheres, negros, homossexuais e pessoas portadoras de deficiência. 2. ed. Belo Horizonte: Del Rey, 2005.

DE MELLO, Celso Antônio Bandeira. O conteúdo jurídico do princípio da igualdade. São Paulo: Malheiros, 2002.

FERREIRA FILHO, Manuel Gonçalves. Direitos humanos fundamentais. 12 ed. São Paulo: Saraiva, 2010.

FREHSE, Fraya. Da desigualdade social nos espaços públicos Centrais Brasileiros.Disponível em: <http://www.scielo.br/scielo.php?script=sci_arttext\&pid=S2238$38752016000100129 \&$ lang=pt>. Acesso em 27 abr. 2017. 
LENZA, Pedro. Direito constitucional esquematizado. $20^{a}$ ed. São Paulo: Saraiva, 2016.

LIMA, Alceu Amoroso. Os direitos do homem e o homem sem direitos. 2. ed. Rio de Janeiro: vozes, 1999.

PIOVESAN, Flavia. Ações afirmativas e direitos humanos, REVISTA USP, São Paulo, n.69, p. 36-43, março/maio 2006, disponível em: <http://www.revistas.usp.br/revusp/article/viewFile/13511/15329>. Acesso em 28 abr. 2017

ONU. Declaração das Nações Unidas sobre a eliminação de todas as formas de discriminação. Disponível em: <https://www.oas.org/dil/port/1963\%20Declara\%C3\%A7\%C3\%A3o\%20da s\%20Na\%C3\%A7\%C3\%B5es\%20Unidas\%20sobre\%20a\%20Elimina\%C3 $\%$ A7\% C3\%A3o\%20de\%20Todas $\% 20$ as\%20Formas\%20de\%20Discrimina $\%$ C3\%A7\%C3\%A3o\%20Racial,\%20proclamada\%20pela\%20Assembleia\% $20 \mathrm{Geral} \% 20 \mathrm{das} \% 20 \mathrm{Na} \% \mathrm{C} 3 \% \mathrm{~A} 7 \% \mathrm{C} 3 \% \mathrm{~B} 5 \mathrm{es} \% 20 \mathrm{Unidas} \% 20 \mathrm{em} \% 2020 \% 2$ 0de\%20novembro\%20de\%201963,\%20a\%20resolu\%C3\%A7\%C3\%A3o\% 201904\%20(XVIII).pdf> . Acesso em 18 mar. 2018.

ONU. Objetivos de Desenvolvimento Sustentável, disponível em: <http://www.estrategiaods.org.br/>. Acesso em 20 abr. 2017.

ONU. Objetivo de Desenvolvimento Sustentável $\mathrm{n}^{\circ} 10$, disponível em: <http://www.estrategiaods.org.br/os-ods/ods10/>. Acesso em 20 abr. 2017.

OXFAM: Relatório: "A distância que nos une." $<$ https://www.oxfam.org.br/sites/default/files/arquivos/Relatorio_A_distanc ia_que_nos_une.pdf>, último acesso em 22 fev. 2018.

PIZZIO, Alex. Embates acerca da ideia de justiça social em relação a conflitos sociais e desigualdades. Disponivel em: $<$ http://www.scielo.br/scielo.php?script=sci_arttext\&pid=S0034-

$76122016000300355 \&$ lang=pt>. Acesso em 25 abr. 2017.

RIBIEIRO, Marcelo Gomes. Desigualdades urbanas e desigualdades sociais nas metrópoles brasileiras. Disponível em: <http://www.scielo.br/scielo.php?script=sci_arttext\&pid=S1517$45222016000200198 \&$ lang=pt $>$. Acesso em 28 abr. 2017.

SANTOS, Município de. Comissão da Diversidade Sexual de Santos. Disponível em: <http://www.santos.sp.gov.br/?q=content/cmds-comissaomunicipal-da-diversidade-sexual-de-santos>. Acesso em 18 mar. 2018.

SÃO PAULO, Assembleia Legislativa do Estado de. Comissão de Defesa dos Direitos da Pessoa Humana, da Cidadania, da Participação e das Questões Sociais. Disponível em: <https://www.al.sp.gov.br/alesp/comissao/?idComissao=12455>. Acesso em 18 mar. 2018. 